\title{
Impact of body mass index on hepatocellular carcinoma recurrence after liver transplantation through long-term follow-up
}

\author{
Nada El-Domiaty ${ }^{1,2}$, Faouzi Saliba ${ }^{1}$, Vincent Karam ${ }^{1}$, Rodolphe Sobesky ${ }^{1}$, Wafaa Ibrahim ${ }^{3}$, Eric Vibert ${ }^{1}$, \\ Gabriella Pittau ${ }^{1}$, Khaled Amer ${ }^{4}$, Maysaa A. Saeed ${ }^{2}$, Jihan A. Shawky ${ }^{2}$, Daniel Cherqui ${ }^{1}$, René Adam ${ }^{1}$, \\ Didier Samuel $^{1}$
}

${ }^{1}$ AP-HP Hôpital Paul Brousse, Hepato-Biliary Centre, INSERM UMR 1193, Université Paris Saclay, Villejuif, France; ${ }^{2}$ Tropical Medicine Department, Faculty of Medicine, Zagazig University, Zagazig, Egypt; ${ }^{3}$ Statistics Department, Faculty of Economics and Political Science, Cairo University, Cairo, Egypt; ${ }^{4}$ Hepato-Biliary and Liver Transplant Department, International Medical Center, Cairo, Egypt

Contributions: (I) Conception and design: F Saliba, N El-Domiaty; (II) Administrative support: All authors; (III) Provision of study material or patients: All authors; (IV) Collection and assembly of data: N El-Domiaty, F Saliba; (V) Data analysis and interpretation: N El-Domiaty, F Saliba, W Ibrahim; (VI) Manuscript writing: All authors; (VII) Revision and final approval: All authors.

Correspondence to: Prof. Faouzi Saliba. AP-HP Hôpital Paul Brousse, Centre Hépato-Biliaire, 12 Avenue Paul Vaillant Couturier 94800, Villejuif, France. Email: faouzi.saliba@aphp.fr.

Background: Obesity is associated with increased oncological risk and outcomes but the evidence surrounding the effect of body mass index (BMI) on increased risk of hepatocellular carcinoma (HCC) recurrence after liver transplantation (LT) is still questionable. The purpose of this retrospective study of a large cohort of adult patients transplanted for HCC was to investigate the effect of BMI on the incidence of HCC recurrence and outcome.

Methods: Data from 427 adult recipients transplanted for HCC between 2000 and 2017 were collected. Patients were classified at time of LT according to the World Health Organization BMI classification into 3 groups; group 1: BMI <25 ( $\mathrm{n}=166)$, group 2: BMI 25-29.9 ( $\mathrm{n}=150)$ and group 3: BMI $\geq 30$ ( $\mathrm{n}=111)$.

Results: There were no significant changes of mean BMI overtime $26.8 \pm 5.0 \mathrm{~kg} / \mathrm{m} 2$ at time of LT and $28.8 \pm 23.1$ at 5 years. The recurrence rates of HCC after LT in the three groups were $19 \%, 16 \%$ and $17 \%$ respectively. The 5, 10 and 15-year recurrence free survival (RFS) rates were respectively 68.6\%, 47.3\% and $40.8 \%$ in group $1,73.3 \%, 66.2 \%$ and $49.5 \%$ in group 2 and $68.8 \%, 57.5 \%$ and $47.7 \%$ in group 3 (log rank $\mathrm{P}=0.47)$.

Conclusions: Recipient BMI at time of transplant and during follow-up didn't impact the incidence of HCC recurrence nor long-term patient survival, irrespective to the status of the patients and their tumor characteristic at time of LT. The present study clearly confirms that obesity should not be considered, when selecting patients with HCC to LT, as a predictive factor of recurrence.

Keywords: Hepatocellular carcinoma (HCC); obesity; body mass index (BMI); nutrition; liver transplantation (LT); hepatocellular carcinoma recurrence (HCC recurrence)

Submitted Jan 24, 2020. Accepted for publication Mar 26, 2020.

doi: $10.21037 / \mathrm{hbsn} .2020 .04 .01$

View this article at: https://dx.doi.org/10.21037/hbsn.2020.04.01

\section{Introduction}

Hepatocellular carcinoma (HCC) is one of the most lethal human malignant tumor with $>600,000$ deaths per year worldwide making it the third leading cause of cancer related death $(1,2)$. Over the past quarter century, LT has been established as a durable therapy as it provides complete oncologic resection and correction of the underlying liver disease (3). Major risk factors of HCC are infection with hepatitis $\mathrm{B}(\mathrm{HBV})$, hepatitis $\mathrm{C}(\mathrm{HCV})$, excess 
alcohol intake, obesity, diabetes and metabolic diseases (4). Despite the development of several scores to select patients for LT, the Milan criteria (MC) (single nodule smaller than $5 \mathrm{~cm}$ or from two to three nodules of up to $3 \mathrm{~cm}$ ) are still the most commonly used criteria (5). Tumor recurrence (TR) still occurs in $15 \%$ to $20 \%$ of cases, being associated with unfavorable prognosis $(6,7)$. Therefore, it is necessary to identify other risk factors for recurrence to refine patient selection and to identify modifiable factors that may reduce the incidence of TR.

Liver transplant recipient BMI has been evaluated as a post-transplant prognostic factor on several occasions, with contradictory results regarding the impact of obesity. Because the burden of disease caused by obesity is largely related to the metabolic syndrome and its cardiovascular consequences, it is questionable whether obesity has a similar impact on thoroughly selected patients such as liver transplant candidates compared with the general population (8-12).

Siegel et al. (2012) showed that $25 \%$ of patients with HCC who underwent LT were obese and had twice the risk of death, a higher frequency of microvascular invasion, and tendency for a higher rate of TR, suggesting that the increased expression of vascular endothelial growth factor (VEGF) induced by the adipose tissue may stimulate tumor angiogenesis (13). Mathur et al. (2013) has confirmed the increased risk of TR, with smaller recurrence free survival (RFS) among overweight patients, suggesting that obesity induces a pro-oncogenic state, via reduction of adiponectin and increase of leptin, which would stimulate HCC proliferation, migration, and invasion (14). While some studies declared that the obesity had no clear impact on posttransplant outcome, and high BMI should not be seen as a formal contra-indication for LT (15) there is a paucity of evidence evaluating the impact of BMI, used as a surrogate measure for obesity, on the occurrence of post-operative complications and oncologic outcomes in patients with HCC undergoing LT. Consequently, the main objective of this study was to evaluate in a large cohort of adult patients transplanted for HCC the relationship between recipient $\mathrm{BMI}$ at the time of LT and the incidence and time of HCC recurrence, as well as RFS and survival time after recurrence. We present the following article in accordance with the STROBE reporting checklist (available at https://hbsn. amegroups.com/article/view/10.21037/hbsn.2020.04.01/rc).

\section{Methods}

\section{Data source and patient variables}

This is a retrospective cohort study that recruited all patients transplanted for hepatocellular carcinoma at the Hepato-Biliary Center of Paul Brousse Hospital, France, during the period between January 2000 and December 2017. The data were collected from charts and the electronic database system. The study was approved by institutional local ethics board (registration number 16.4.014). Informed consent was waived in relation to the retrospective design of the study. The study was conducted in accordance with the Declaration of Helsinki (as revised in 2013). Of the 567 patients transplanted for liver cancer, 469 patients were transplanted for HCC (82.7\%). We excluded those patients who underwent a second transplant for any cause $(\mathrm{n}=28)$, combined liver-Kidney transplant $(\mathrm{n}=8)$ and those with missing data for BMI $(\mathrm{n}=6)$. Patients with incidental HCC were not included in the study. Overall, the total number of patients included in this study was 427 patients. Patients were followed till December 2018.

Data comprised recipient's demographics including age, sex, and preoperative medical history of diabetes mellitus, alcohol intake and etiology of liver disease in addition to the BMI. Recipient factors at time of LT including calculated model for end-stage liver disease (MELD) score (16) and child-Pugh score (17) and biochemical parameters like serum albumin $(\mathrm{g} / \mathrm{L})$, estimated glomerular filtration rate (eGFR) $\left(\mathrm{mL} /\right.$ minute $\left./ 1.73 \mathrm{~m}^{2}\right)$ and alpha-fetoprotein (AFP) $(\mu \mathrm{g} / \mathrm{L})$ levels were documented. Tumor characteristics at time of transplant and the final pathology of the native liver (size, and number of nodules, tumor differentiation and microvascular invasion) were all considered. Classification according to Milan criteria (5), University of California San Francisco (UCSF) criteria (18) and AFP score (19) were all recorded.

\section{Preoperative tumor assessment while on waiting list and selection for liver transplantation}

In our center, the decision to treat and the type of treatment were discussed in a weekly multidisciplinary meeting that involve liver surgeons, hepatologists, radiologists, oncologists and pathologists. While on the waiting list, all patients were re-assessed every 3 months clinically, with 
AFP level and imaging using either computed tomography scan (CT) of the chest and abdomen, magnetic resonance imaging (MRI) and Fluorine-18 Fluorodeoxyglucose positron emission tomography (18F-FDG PET) scan and ${ }^{11} \mathrm{C}$-choline if needed, to rule out tumor progression or need for further treatment. To consider a patient on the waiting list we applied initially the Milan criteria based on the last imaging prior to transplant but since 2014, we applied the AFP score that has to be $\leq 2$ (19). Patients were treated with liver resection, trans-arterial chemoembolization (TACE), radio-frequency ablation (RFA), rarely percutaneous ethanol injection or systemic chemotherapy as bridging or downstaging therapy following the Barcelona Clinic Liver Cancer (BCLC) classification guidelines.

\section{Postoperative surveillance and HCC recurrence diagnosis}

Thoraco-abdominal-pelvic CT scan was performed every 4 months for the first 2 years of follow-up, then every 6 months till the end of the fifth year. Thereafter, CT scan was performed annually till ten years or if symptoms occurred. Diagnosis of tumor recurrence was based on imaging. A biopsy was performed if the image was inconclusive.

Detailed follow-up protocols based on the relative risk of HCC recurrence have been published previously, measurement of AFP was routinely performed at outpatient clinic visits and the general principles of treatment for recurrent HCC lesions were applied to LT recipients with HCC recurrence (20). HCC recurrence was defined as direct detection of metastatic lesion(s) by imaging study and pathological confirmation by biopsy.

\section{Study design}

Patients were classified into three BMI groups at the time of transplant according to the BMI classification which is established by the WHO (21) into group 1: non-obese (BMI $<25 \mathrm{~kg} / \mathrm{m}^{2}$ ); group 2: overweight (BMI $25-29.9 \mathrm{~kg} / \mathrm{m}^{2}$ ) and group 3: obese (BMI $\geq 30 \mathrm{~kg} / \mathrm{m}^{2}$ ). Time frames at diagnosis of HCC, at listing and at time of transplant were noted. Data were collected after transplant at different time visits at $1,3,5,10$ and 15 years after LT.

\section{Outcomes}

The primary outcome of the study was to establish the incidence of HCC recurrence according to BMI group.
The secondary outcomes were patient and recurrence free survival and the post recurrence survival according to the recipient BMI class through a long-term follow-up.

\section{Statistical analysis}

For each variable, we only used data that were $>80 \%$ completed with no data imputation for statistical analysis. Statistical analysis was performed using SPSS version 18 (SPSS, Inc., Chicago, IL, USA) and R software version 3.4.4. Continuous and categorial variables were analyzed using the F-test and the Pearson's chi-squared test, respectively. Overall survival was assessed according to Kaplan-Meier methods with the log-rank test. Significance was accepted with $\mathrm{P}$ value $<0.05$ and $95 \%$ confidence. Quantitative data were expressed by either the mean \pm standard deviation (SD) or the median and inter quartile range (Q3-Q1) (IQR). Qualitative variables were expressed as percentages and frequencies.

\section{Results}

\section{Patient's characteristics}

A total of 427 patients with a mean age of $57.8 \pm 8.5$ years (83.8\% were males) who underwent LT for HCC were recruited. Based on BMI at LT, there were 166 (38.8\%) non-obese patients group 1, $150(35.1 \%)$ overweight group 2 and 111 (25.9\%) obese group 3. The mean follow-up was $74.6 \pm 58.6$ months. Patient's demographic data, clinical history and etiology of the underlying liver disease in the 3 groups are summarized in Table 1.

Age, history of chronic alcoholism and diabetes mellitus were significantly higher between both the overweight and obese groups. HCV cirrhosis was the common etiology followed by alcoholic cirrhosis. Non-alcoholic steatohepatitis (NASH) and alcoholic cirrhosis were significantly more common among the overweight and obese groups. The mean serum AFP level $(\mu \mathrm{g} / \mathrm{L})$ at time of HCC diagnosis was significantly different respectively in the 3 groups $(662 \pm 285$ vs. $166 \pm 198 v s .62 \pm 195 \mu \mathrm{g} / \mathrm{L}$; $\mathrm{P}=0.038)$. However, there were no anymore differences in the pre transplant serum AFP across the three groups. The mean preoperative MELD score $(13.5 \pm 7.4 v s .13 .1 \pm 7.1 v s$. 14.8 \pm 6.7 ) didn't differ among the three BMI groups. Most of the patients had a preoperative Child-Pugh score B (42.4\%, $41.6 \%$, and $37.6 \%$, respectively; $\mathrm{P}=0.345$ ).

The post-operative immunosuppression regimen was 
Table 1 Patient and tumor characteristics according to BMI category

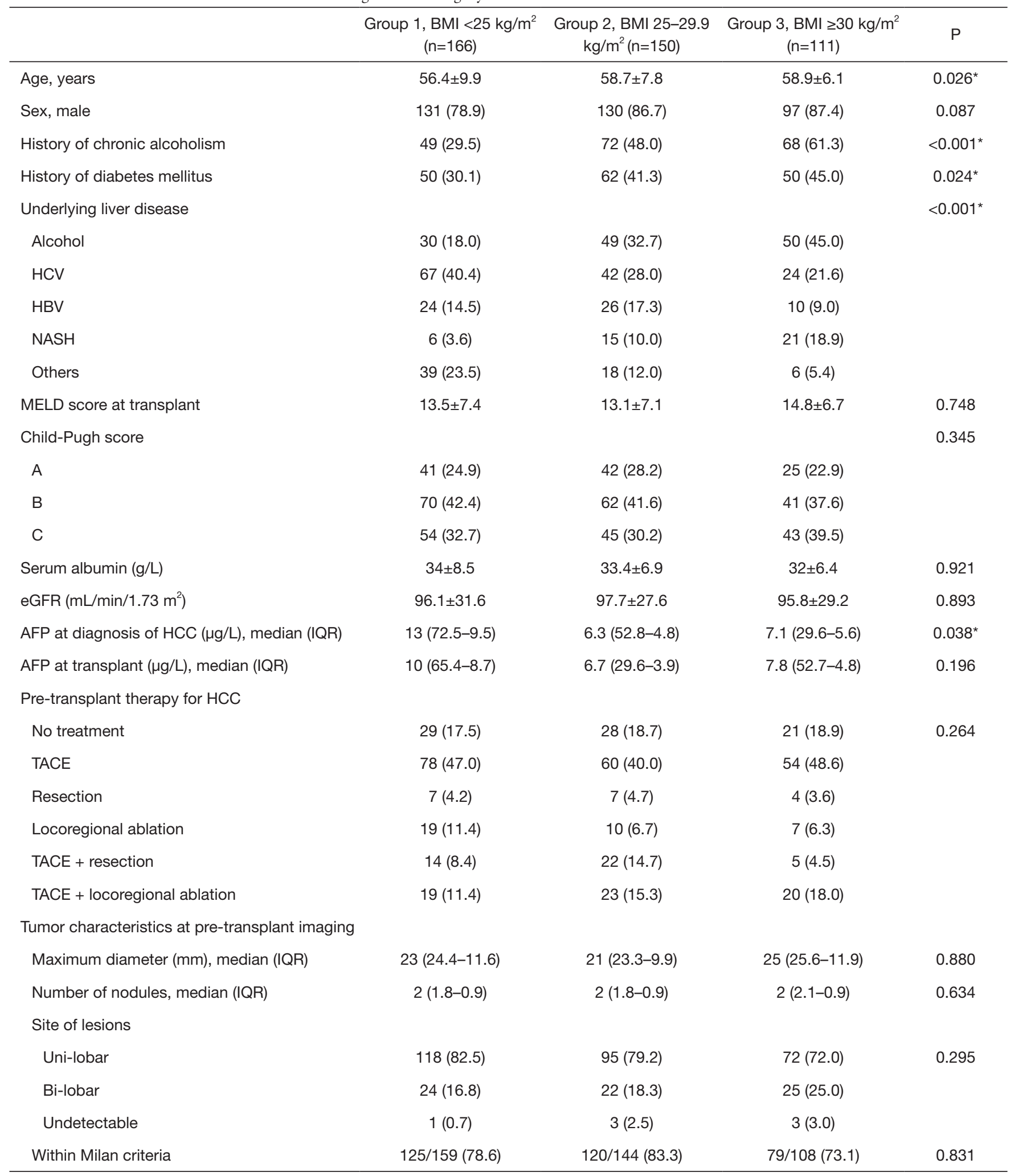

Table 1 (Continued) 
Table 1 (Continued)

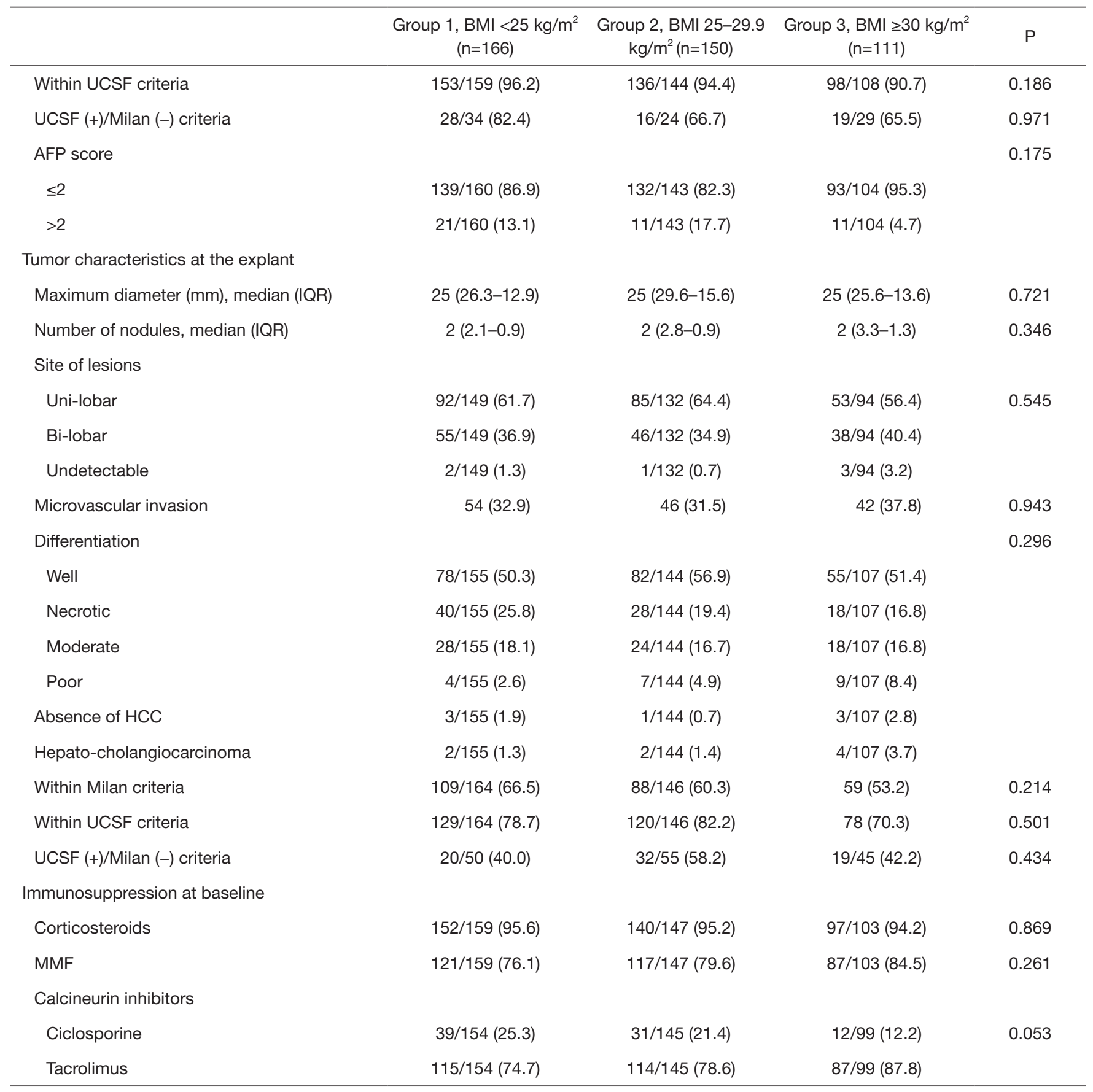

Continuous variables are expressed as either mean \pm SD or IQR (Q3-Q1). Categorical variables as $n$ (\%) and all the percentages are calculated out of available data. *, significant. HCV, hepatitis C; HBV, hepatitis B; NASH, non-alcoholic steatohepatitis; BMI, body mass index; HCC, hepatocellular carcinoma; UCSF, University of California San Francisco. 
similar among the three groups; corticosteroids (95.6\% vs. $95.2 \%$ vs. $94.2 \%$, respectively, $\mathrm{P}=0.869)$, mycophenolic acid $(76.1 \%$ vs. $79.6 \%$ vs. $84.5 \%$, respectively, $\mathrm{P}=0.261)$ and for calcineurin inhibitors: $74.7 \%, 78.6 \%$ and $87.8 \%$ of the patients respectively were on tacrolimus while $25.3 \%$, $21.4 \%$ and $12.2 \%$ respectively were on cyclosporine (Table 1).

\section{Tumor characteristics}

\section{Tumor characteristics at time of HCC diagnosis}

The first evaluation of HCC at time of diagnosis showed no significant differences respectively in the non-obese, overweight and obese groups in tumor size $(28.0 \pm 17.6 \mathrm{vs}$. $30.2 \pm 22.7$ vs. $27.2 \pm 11.4 \mathrm{~mm}, \mathrm{P}=0.548)$ and tumor burden (1.8 \pm 1.4 vs. $1.9 \pm 4.2$ vs. $1.7 \pm 0.9$, respectively, $\mathrm{P}=0.856)$. The majority of patients exhibited comparable AFP score of $\leq 2$ in the three groups $(83.6 \%, 83.3 \%$ and $90.3 \%$, respectively; $\mathrm{P}=0.598)$. The waiting time between the first diagnosis of HCC and liver transplant was not different across the three groups $(21.1 \pm 21.7$ vs. $24.8 \pm 20.2$ vs. $21.6 \pm 19.9$ months respectively, $\mathrm{P}=0.354)$. Similar proportion of patients requiring preoperative downstaging/bridging therapy was observed among the three groups $(\mathrm{P}=0.264)$; trans-arterial chemoembolization (TACE) was the commonest used procedure ( $47 \%$ vs. $40 \%$ vs. $48.6 \%$ ) respectively in the three groups (Table 1).

\section{Tumor characteristics at time of transplant}

There were no significant differences on imaging (CT scan and/or MRI) at time of transplant across the three groups in respect to the largest tumor diameter $(\mathrm{P}=0.880)$, number of nodules $(\mathrm{P}=0.634)$ and site of the tumor $(\mathrm{P}=0.295)$ (Table 1). The majority of the patients among the three groups was respectively within the Milan criteria (78.6\% vs. $83.3 \%$ vs. $73.1 \% ; \mathrm{P}=0.831)$ and had an AFP score of $\leq 2$ (86.9\% vs. $82.3 \%$ vs. $95.3 \% ; \mathrm{P}=0.175)$.

\section{Tumor characteristics at explant pathology}

The pathological evaluation of the explant (Table 1) revealed no significant differences respectively in the non-obese, overweight and obese groups regarding largest tumor diameter $(27.3 \pm 19.1$ vs. $28.6 \pm 19.4$ vs. $27.1 \pm 13.8 \mathrm{~mm}$, $\mathrm{P}=0.721)$, tumor burden $(2.7 \pm 3.0$ vs. $3.1 \pm 4.9$ vs. $3.6 \pm 5.3$, respectively, $\mathrm{P}=0.346$ ) and microvascular invasion (MVI) (32.9\% vs. $31.5 \%$ vs. $37.8 \%$, respectively, $\mathrm{P}=0.943$ ). There were fewer patients with unilobar lesions in the three groups $(61.7 \%$ vs. $64.4 \%$ vs. $56.4 \%$, respectively; $\mathrm{P}=0.545)$ as compared to imaging evaluation at time of transplant ( $82.5 \%$ vs. $79.2 \%$ vs. $72 \%$, respectively, $\mathrm{P}=0.295$ ). Merely half of the patients had a well-differentiated HCC, with comparable values among the three groups $(\mathrm{P}=0.296)$. Overall, numerically more patients were beyond Milan criteria in the obese group at pathology, but no significant difference was observed among the three groups $(30.5 \% v$ s. $37.7 \%$ vs. $40.5 \%$, respectively, $\mathrm{P}=0.214$ ).

\section{BMI changes after transplantation}

In the overall population, there was a significant difference between the mean BMI respectively at time of transplant and that after 1 year of LT $\left[26.8 \pm 5.0 \mathrm{~kg} / \mathrm{m}^{2}\right.$; IQR $(23.2-$ $30.1)]$ vs. $\left[26.3 \pm 4.8 \mathrm{~kg} / \mathrm{m}^{2}\right.$; IQR (22.8-29.4); paired t-test $\mathrm{P}$ value $<0.0001]$. Afterwards, non-significant changes occurred in mean BMI (Figure 1). Despite that the mean BMI after 1 year of LT was mildly different from baseline, BMI at 1 year didn't affect long-term HCC recurrence.

\section{HCC recurrence: incidence, patterns and treatments}

The incidence of HCC recurrence was not different among the three groups and was respectively in the non-obese, overweight and obese groups $18.7 \%, 16 \%$ and $17.1 \%$ $(\mathrm{P}=0.819)$. The site of recurrence was predominantly extrahepatic in $61.3 \%$ of the patients and was not different among the three groups (Table 2).

The main treatment of HCC recurrence among the three groups was mainly based on chemotherapy using either Gemcitabine plus Oxaliplatin initially then Sorafenib after its licence on the market $(51.6 \%, 85 \%$ and $87.4 \%$ respectively) with very poor results. Few patients who developed extrahepatic recurrence (lung, bone, lymph nodes and adrenal glands) underwent different combinations of therapies (chemotherapy, loco-regional treatment and radiotherapy) and only 10 patients with either intrahepatic HCC or lung metastasis recurrence underwent surgical resections (Table 2).

The overall survival and post-HCC recurrence survival The 1-year mortality rate that could reflect surgical outcome was respectively $9.5 \%, 7.4 \%$ and $9.2 \%$ in the non-obese, overweight and obese groups. Biliary complications occurred respectively in $7.2 \%, 2.0 \%$ and $4.5 \%$. The incidence of hepatic arterial thrombosis was $1.2 \%, 2.0 \%$ and $0.9 \%$.

The 5 and 10 -year patient survival rates were not different among the three groups and were respectively (72.9\% vs. $74.8 \%$ vs. $75.7 \%$ and $51.6 \%$ vs. $67.9 \%$ vs. $59.5 \%$; $\log$ rank $\mathrm{P}=0.66$ ) (Figure 2). The 5- and 10-year patient 


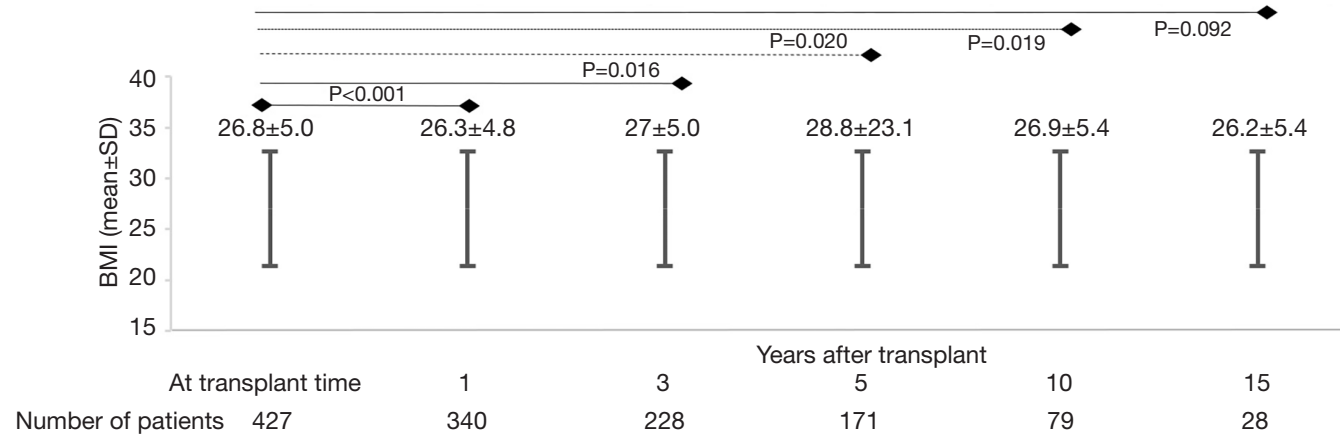

Figure 1 BMI changes over the follow-up years (mean $\pm \mathrm{SD}$; paired $t$-tests were performed at each follow up visit and compared to baseline). BMI, body mass index.

Table 2 HCC recurrence: patterns, treatments and outcomes

\begin{tabular}{|c|c|c|c|c|}
\hline & $\begin{array}{c}\text { Group 1, BMI <25 kg/m² } \\
\qquad(\mathrm{n}=166)\end{array}$ & $\begin{array}{c}\text { Group 2, BMI 25-29.9 kg/ } \\
\mathrm{m}^{2}(\mathrm{n}=150)\end{array}$ & $\begin{array}{c}\text { Group 3, BMI } \geq 30 \mathrm{~kg} / \mathrm{m}^{2} \\
(\mathrm{n}=111)\end{array}$ & $P$ \\
\hline Incidence of recurrence & $31(18.7)$ & $24(16.0)$ & $19(17.1)$ & 0.819 \\
\hline Site of recurrence & & & & 0.162 \\
\hline Extrahepatic & 20/31 (64.5) & $15 / 24(62.5)$ & $11 / 19(57.9)$ & \\
\hline AFP level at recurrence $(\mu \mathrm{g} / \mathrm{L})$, median (IQR) & $65(122.4-43.5)$ & $40(110.6-29.6)$ & $60(99.3-30.4)$ & 0.667 \\
\hline \multicolumn{5}{|l|}{ Treatment of HCC recurrence } \\
\hline Radiotherapy & $2 / 31(6.5)$ & 0 & $1 / 16(6.3)$ & \\
\hline Surgical resection & $2 / 31(6.5)$ & 0 & 0 & \\
\hline Surgical resection + radiotherapy & $1 / 31(3.2)$ & $1 / 20(5.0)$ & 0 & \\
\hline Patient survival (months) & $69 \pm 57.3$ & $70.37 \pm 57.4$ & $62.08 \pm 53.9$ & 0.487 \\
\hline RFS (months) & $67.6 \pm 58.4$ & $62.6 \pm 57.6$ & $62.5 \pm 54$ & 0.676 \\
\hline Mortality & $54(33.1)$ & $44(29.5)$ & $34(30.9)$ & 0.787 \\
\hline
\end{tabular}

Continuous variables are expressed as either mean \pm SD or IQR (Q3-Q1). Categorical variables as $\mathrm{n}$ (\%) and all the percentages are calculated out of available data. HCC, hepatocellular carcinoma; BMI, body mass index.

RFS rates were comparable among the groups and were respectively $(68.6 \%$ vs. $73.3 \%$ vs. $68.8 \%$ and $47.3 \%$ vs. $66.2 \%$ vs. $57.5 \%$; $\log \operatorname{rank} \mathrm{P}=0.47$ ) (Figure 3).

As it could be expected, the patient survival after diagnosis of HCC recurrence was poor without statistically significant difference among the groups with a median survival respectively of 11,18 and 15 months. The 3and 5 -year patient survival rates after recurrence were respectively $14.4 \%$ vs. $18.6 \%$ vs. 20.5 and $7 \%$ vs. $9.3 \%$ vs. $10.2 \% ; \mathrm{P}=0.66$ (Figure 4). 

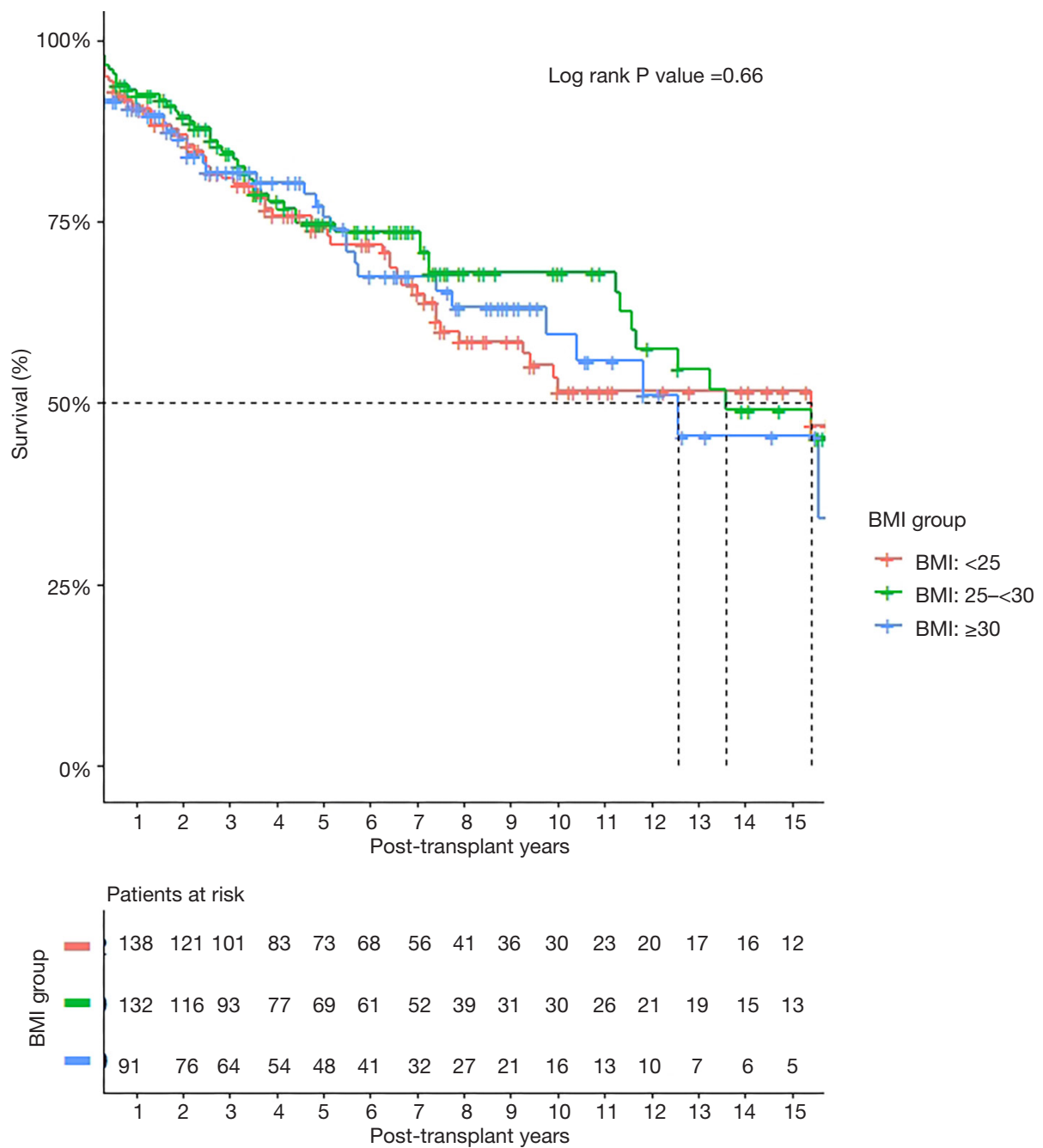

Figure 2 Kaplan-Meier survival curves after liver transplantation for HCC according to BMI groups (10-year survivals were 51.6\%, 67.9\% and 59.5\%). HCC, hepatocellular carcinoma; BMI, body mass index.

\section{Discussion}

In view of the controversial and debatable effect of BMI on survival rate and the recurrence of HCC after LT, this retrospective study of a large cohort of patients transplanted for HCC showed the absence of impact of BMI on HCC recurrence after liver transplantation. There was also no difference among the three groups of BMI (normal weight, overweight and obese patients) when analyzing time to recurrence, patient survival from transplant and patient survival after recurrence.

Despite the strict selection criteria, tumor recurrence still occurs in $15-20 \%$ of patients transplanted for HCC $(6,7)$. Our data revealed comparable recurrence ranges within the three BMI groups with no statistical difference among BMI groups ranging from $16 \%$ to $19 \%$. To our knowledge, few papers reported on the impact of obesity on HCC recurrence. Mathur et al. (2013) reported that the incidence of recurrence of HCC was doubled in the presence of overweight and obesity compared to nonobesity, with a significant decrease in the time to recurrence following LT for HCC (14). The decrease in adiponectin coupled with the increase in leptin, in the setting of obesity, synergistically enhances HCC proliferation, migration and invasiveness. This may account for the earlier occurrence and increased incidence of recurrence of HCC in the setting of obesity following LT (14). The mean time of recurrence in our cohort in both overweight and obese groups was 62.5 versus 67.6 months in the non-obese group and this was not 


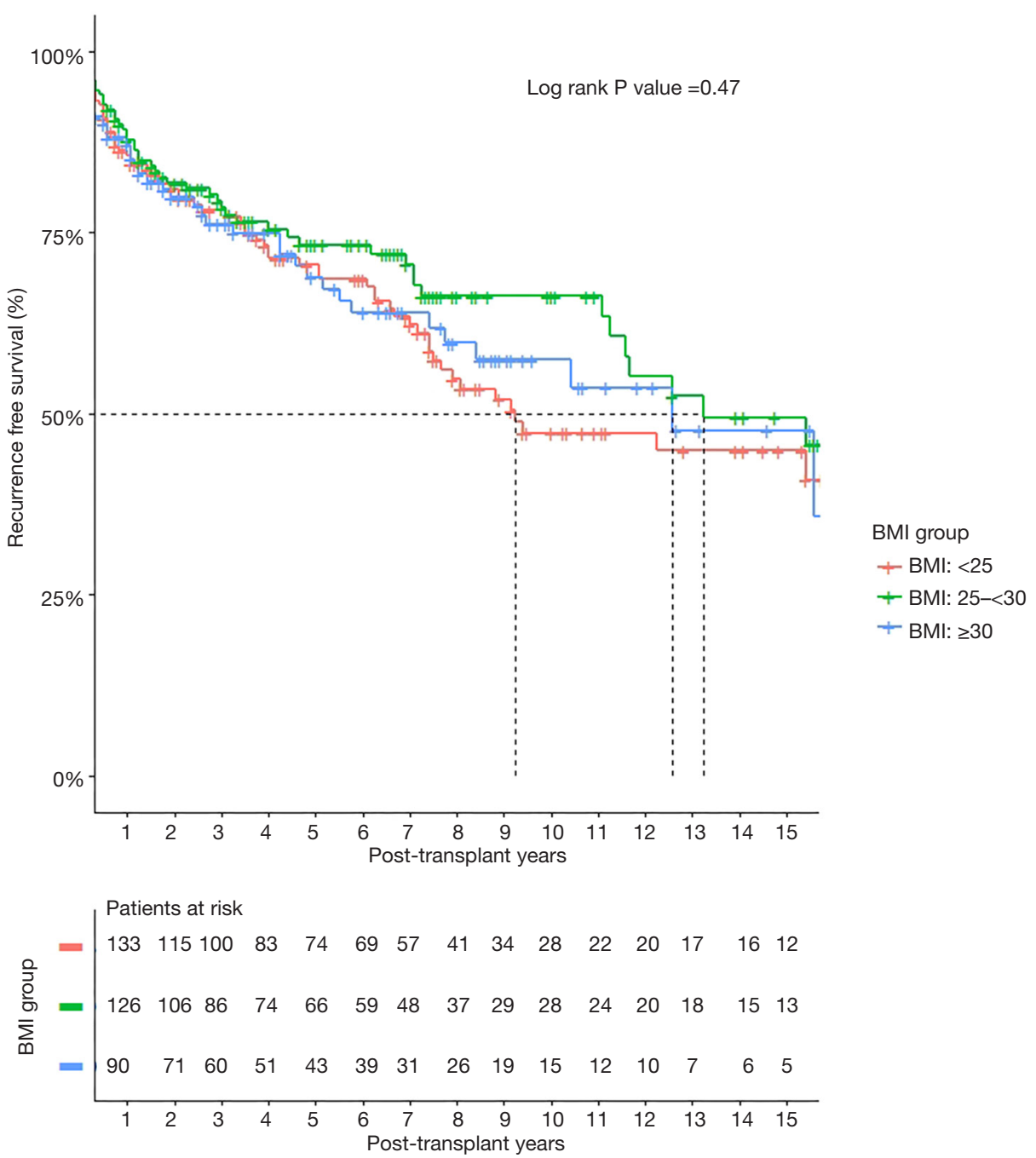

Figure 3 Kaplan-Meier recurrence free survival curves after liver transplantation for HCC according to BMI groups (10-year RFS were $47.3 \%, 66.2 \%$ and $57.5 \%)$. HCC, hepatocellular carcinoma; BMI, body mass index.

significant $(\mathrm{P}=0.67)$.

The etiology, in transplant recipients of group 2 (BMI $\left.25-29.9 \mathrm{~kg} / \mathrm{m}^{2}\right)$ and group $3\left(\mathrm{BMI} \geq 30 \mathrm{~kg} / \mathrm{m}^{2}\right)$, was mostly due to alcoholic cirrhosis or NASH while in the nonobese patient group 1 (BMI $<25 \mathrm{~kg} / \mathrm{m}^{2}$ ) HCV was more common. This trend is similar to nationwide trends in the etiology of liver disease in obese transplant recipients (9). Data on 18,000 transplant recipients has demonstrated that severe $\left(\mathrm{BMI} \geq 35 \mathrm{~kg} / \mathrm{m}^{2}\right)$ and morbid (BMI $\geq 40 \mathrm{~kg} / \mathrm{m}^{2}$ ) obesity were associated with significant increased incidence of cryptogenic steatohepatitis and NASH (22). The three groups were comparable in terms of their MELD score, tumor characteristics at time of transplant, AFP levels. At explant pathology, the relationship between increased MVI and BMI has previously been considered. Siegel et al. (2012) showed that patients with MVI had poor survivals than other patients and those with a BMI $>30$ were more likely to have MVI than those with lower BMI and hence increased recurrence risk and worsened survival (13). Few studies have shown that vascular invasion in HCC is associated with markers of angiogenesis such as VEGF expression $(23,24)$. A possible explanation for the relationship between increased MVI and BMI is via increased expression of adipokines in patients with higher BMI. Adipose tissue has been shown to induce expression of VEGF and other cytokines in human and animal models (25). In our study we didn't find 


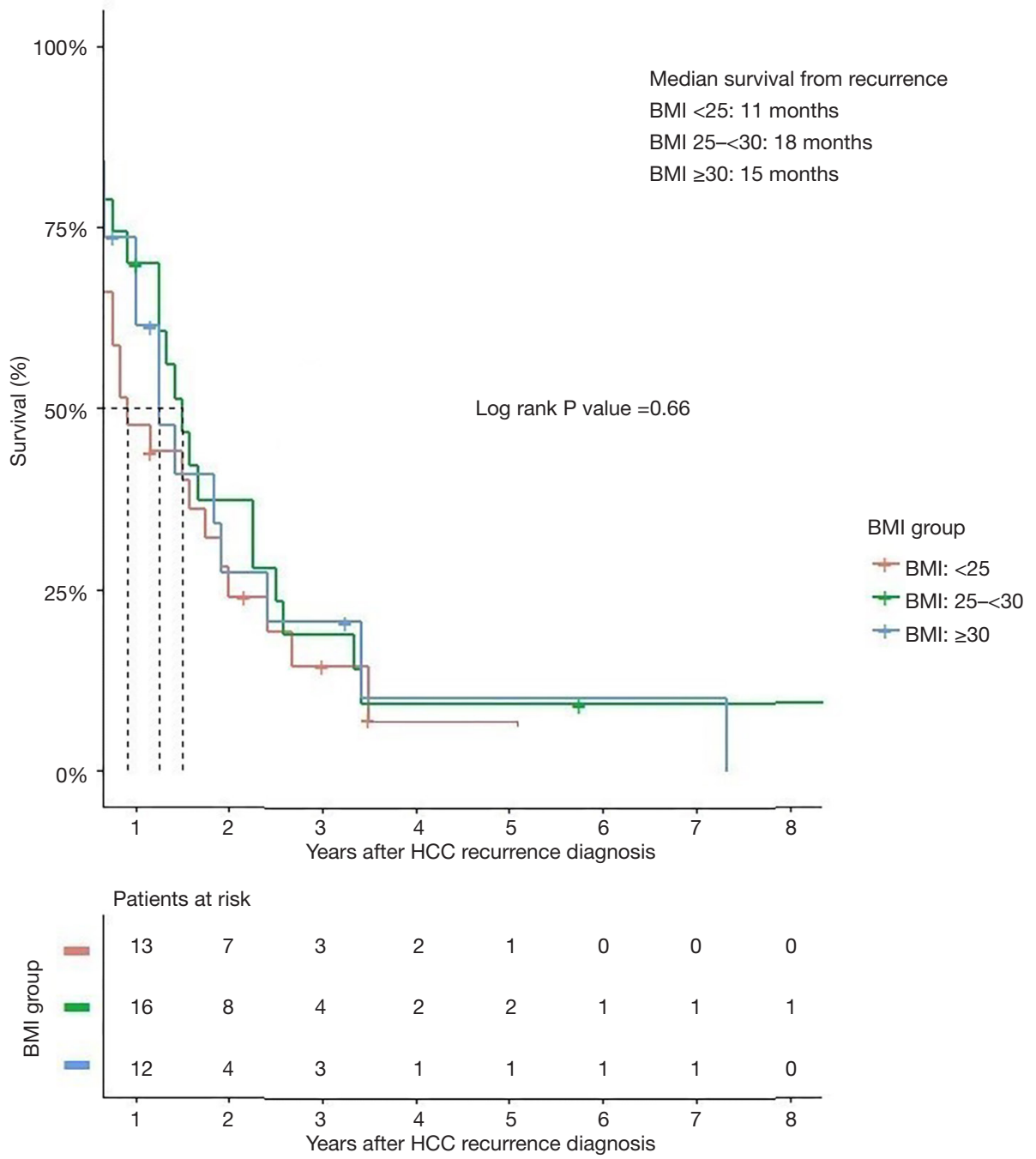

Figure 4 Kaplan-Meier patient survival curves after diagnosis of HCC recurrence according to BMI groups (5-year post recurrence survivals were $7 \%, 9.3 \%$ and $10.2 \%$ ). HCC, hepatocellular carcinoma; BMI, body mass index.

difference among the three groups on pathology of the explant liver in terms of tumor differentiation, lesion size, number of nodules and MVI.

In this study, $39 \%$ of the recurrences occurred in the liver itself following LT. Marsh et al. (1997) (26) and Mathur et al. (2013) (14) demonstrated comparable percentages with respectively $35 \%$ and $42 \%$ of recurrences occurring within the transplanted liver itself and this was not influenced by BMI.

Through our long term patients follow-up, we recorded that the 10 years survival rates were comparable among the non-obese (51.6\%), overweight (67.9\%) and obese (59.5\%) groups; these results are aligned with what is reported by several institutions which confirmed that BMI of $\geq 30 \mathrm{~kg} / \mathrm{m}^{2}$ is not associated with a decrease in survival (27). However, the smaller sample size of patients with BMI $\geq 35 \mathrm{~kg} / \mathrm{m}^{2}$ $(n=28)$ in our study did not allow elucidation of differences in survival between severely obese patients (BMI $\geq 35 \mathrm{~kg} / \mathrm{m}^{2}$ ) and morbid obese (BMI of $\geq 40 \mathrm{~kg} / \mathrm{m}^{2}$ ). In the two large UNOS studies, the first demonstrated decreased survival in severely (BMI $\geq 35 \mathrm{~kg} / \mathrm{m}^{2}$ ) and morbid obese (BMI of $\geq 40 \mathrm{~kg} / \mathrm{m}^{2}$ ) groups (9) and the second indicated that BMI of $\geq 35 \mathrm{~kg} / \mathrm{m}^{2}$ was a significant predictor of negative outcomes at both the 1-month and 1-year time-points following liver transplantation (28).

The study has some limitations mainly in relation to the 
dry body weight and BMI at time of transplant that could be affected by other confounders such as the presence of edema and ascites. Dry weight is somewhat difficult to be assessed in these patients and this had been a limitation in several studies. To note, that the number of patients with Child-Pugh score B and C who most likely could present with ascites were comparable among the three groups (Table 1). Ideally, as previously reported, muscle mass (based on pretransplant computed tomography) is a better predictor of post-LT survival as $62 \%$ of the patients with a BMI $\geq 25 \mathrm{~kg} / \mathrm{m}^{2}$ were cachectic, compared with $80 \%$ of the patients with a BMI of 18.5 to 24.9 (29).

In conclusion, this study is the first to close examine the relationship between BMI values and the HCC recurrence after LT for HCC through long-term follow-up. The results of the present work in keeping with evidences from literature revealed that: (I) recipient's BMI at time of transplant had no direct impact on the incidence of HCC recurrence after LT through long-term follow up regardless the status of the patients and their tumor characteristic at time of transplant; (II) the overall 5-10 year patient survival and the 5-year patient survival after the diagnosis of the HCC recurrence were comparable among the non-obese, obese and overweight patients. The present study clearly confirms that obesity should not be considered, when selecting patients with HCC to LT, as a predictive factor of recurrence.

\section{Acknowledgments}

Funding: None.

\section{Footnote}

Reporting Checklist: The authors have completed the STROBE reporting checklist. Available at https://hbsn. amegroups.com/article/view/10.21037/hbsn.2020.04.01/rc

Data Sharing Statement: Available at https://hbsn. amegroups.com/article/view/10.21037/hbsn.2020.04.01/dss

Conflicts of Interest: All authors have completed the ICMJE uniform disclosure form (available at https://hbsn. amegroups.com/article/view/10.21037/hbsn.2020.04.01/coif). Dr. FS serves as the unpaid editorial board members of Hepatobiliary Surgery and Nutrition. The other authors have no conflicts of interest to declare.
Ethical Statement: The authors are accountable for all aspects of the work in ensuring that questions related to the accuracy or integrity of any part of the work are appropriately investigated and resolved. The data were collected from charts and the electronic database system. The study was approved by institutional local ethics board (registration number 16.4.014). Informed consent was waived in relation to the retrospective design of the study. The study was conducted in accordance with the Declaration of Helsinki (as revised in 2013).

Open Access Statement: This is an Open Access article distributed in accordance with the Creative Commons Attribution-NonCommercial-NoDerivs 4.0 International License (CC BY-NC-ND 4.0), which permits the noncommercial replication and distribution of the article with the strict proviso that no changes or edits are made and the original work is properly cited (including links to both the formal publication through the relevant DOI and the license). See: https://creativecommons.org/licenses/by-nc-nd/4.0/.

\section{References}

1. Ferlay J, Soerjomataram I, Dikshit R, et al. Cancer incidence and mortality worldwide: sources, methods and major patterns in GLOBOCAN 2012. Int J Cancer 2015;136:E359-86.

2. Lee Y, Park H, Lee H, et al. The Clinicopathological and Prognostic Significance of the Gross Classification of Hepatocellular Carcinoma. J Pathol Transl Med 2018;52:85-92.

3. Busuttil RW, Farmer DG, Yersiz H, et al. Analysis of long-term outcomes of 3200 liver transplantations over two decades: a single-center experience. Ann Surg 2005;241:905-16; discussion 916-8.

4. El-Serag HB. Hepatocellular carcinoma. N Engl J Med 2011;365:1118-27.

5. Mazzaferro V, Regalia E, Doci R, et al. Liver transplantation for the treatment of small hepatocellular carcinomas in patients with cirrhosis. $\mathrm{N}$ Engl J Med 1996;334:693-9.

6. de'Angelis N, Landi F, Carra MC, et al. Managements of recurrent hepatocellular carcinoma after liver transplantation: A systematic review. World J Gastroenterol 2015;21:11185-98.

7. Bodzin AS, Lunsford KE, Markovic D, et al. Predicting Mortality in Patients Developing Recurrent Hepatocellular 
Carcinoma After Liver Transplantation: Impact of Treatment Modality and Recurrence Characteristics. Ann Surg 2017;266:118-25.

8. Dick AA, Spitzer AL, Seifert CF, et al. Liver transplantation at the extremes of the body mass index. Liver Transpl 2009;15:968-77.

9. Nair S, Verma S, Thuluvath PJ. Obesity and its effect on survival in patients undergoing orthotopic liver transplantation in the United States. Hepatology 2002;35:105-9.

10. Pelletier SJ, Schaubel DE, Wei G, et al. Effect of body mass index on the survival benefit of liver transplantation. Liver Transpl 2007;13:1678-83.

11. Nair S, Vanatta JM, Arteh J, et al. Effects of obesity, diabetes, and prior abdominal surgery on resource utilization in liver transplantation: a single-center study. Liver Transpl 2009;15:1519-24.

12. Leonard J, Heimbach JK, Malinchoc M, et al. The impact of obesity on long-term outcomes in liver transplant recipients-results of the NIDDK liver transplant database. Am J Transplant 2008;8:667-72.

13. Siegel AB, Lim EA, Wang S, et al. Diabetes, body mass index, and outcomes in hepatocellular carcinoma patients undergoing liver transplantation. Transplantation 2012;94:539-43.

14. Mathur A, Franco ES, Leone JP, et al. Obesity portends increased morbidity and earlier recurrence following liver transplantation for hepatocellular carcinoma. HPB (Oxford) 2013;15:504-10.

15. Orci LA, Majno PE, Berney T, et al. The impact of wait list body mass index changes on the outcome after liver transplantation. Transpl Int 2013;26:170-6.

16. Kamath PS, Wiesner RH, Malinchoc M, et al. A model to predict survival in patients with end-stage liver disease. Hepatology 2001;33:464-70.

17. Pugh RN, Murray-Lyon IM, Dawson JL, et al. Transection of the oesophagus for bleeding oesophageal varices. Br J Surg 1973;60:646-9.

18. Yao FY, Ferrell L, Bass NM, et al. Liver transplantation for hepatocellular carcinoma: expansion of the tumor size limits does not adversely impact survival. Hepatology 2001;33:1394-403.

19. Duvoux C, Roudot-Thoraval F, Decaens T, et al. Liver transplantation for hepatocellular carcinoma: a model including $\alpha$-fetoprotein improves the performance of Milan criteria. Gastroenterology 2012;143:986-94.e3; quiz e14-5.

20. Hwang S, Moon DB, Ahn CS, et al. Risk-based long- term screening for hepatocellular carcinoma recurrence after living donor liver transplantation. Transplant Proc 2013;45:3076-84.

21. BMI classification. Available online: http://apps.who.int/ bmi/index.jsp?introPage=intro_3.html. Accessed date: 5 November 2015.

22. Nair S, Eustace J, Thuluvath PJ. Effect of race on outcome of orthotopic liver transplantation: a cohort study. Lancet 2002;359:287-93.

23. Amaoka N, Osada S, Kanematsu M, et al. Clinicopathological features of hepatocellular carcinoma evaluated by vascular endothelial growth factor expression. J Gastroenterol Hepatol 2007;22:2202-7.

24. Li SG, Ye ZY, Zhao ZS, et al. Correlation of integrin beta3 mRNA and vascular endothelial growth factor protein expression profiles with the clinicopathological features and prognosis of gastric carcinoma. World J Gastroenterol 2008; 14:421-7.

25. Rega G, Kaun C, Demyanets S, et al. Vascular endothelial growth factor is induced by the inflammatory cytokines interleukin- 6 and oncostatin $\mathrm{m}$ in human adipose tissue in vitro and in murine adipose tissue in vivo. Arterioscler Thromb Vasc Biol 2007;27:1587-95.

26. Marsh JW, Dvorchik I, Subotin M, et al. The prediction of risk of recurrence and time to recurrence of hepatocellular carcinoma after orthotopic liver transplantation: a pilot study. Hepatology 1997;26:444-50.

27. Sawyer RG, Pelletier SJ, Pruett TL. Increased early morbidity and mortality with acceptable long-term function in severely obese patients undergoing liver transplantation. Clin Transplant 1999;13:126-30.

28. Thuluvath PJ, Yoo HY, Thompson RE. A model to predict survival at one month, one year, and five years after liver transplantation based on pretransplant clinical characteristics. Liver Transpl 2003;9:527-32.

29. DiMartini A, Cruz RJ Jr, Dew MA, et al. Muscle mass predicts outcomes following liver transplantation. Liver Transpl 2013;19:1172-80.

Cite this article as: El-Domiaty N, Saliba F, Karam V, Sobesky R, Ibrahim W, Vibert E, Pittau G, Amer K, Saeed MA, Shawky JA Cherqui D, Adam R, Samuel D. Impact of body mass index on hepatocellular carcinoma recurrence after liver transplantation through long-term follow-up. HepatoBiliary Surg Nutr 2021;10(5):598-609. doi: 10.21037/hbsn.2020.04.01 